DOI: http://dx.doi.org/10.29092/uacm.v18i46.850

\title{
IMAGINARIOS INSTITUYENTES Y CIBERACTIVISMO: UNA LECTURA DESDE CASTORIADIS
}

Francisco Sierra Caballero*

\begin{abstract}
Resumen. La creación digital está en la base definitoria de los nuevos procesos de ruptura protagonizados por los nuevos movimientos urbanos. En el actual ciclo de protestas iniciado en 2011 -de la primavera árabe a Yo soy 132- se observan procesos magmáticos de negatividad, imaginación rebelde y resistencia instituyentes que, en lógica coherencia, demandan de la investigación en comunicación un nuevo marco conceptual para comprender la naturaleza de las transformaciones de los nuevos movimientos sociales. Una lectura crítica del ciberactivismo pasa, en este sentido, por identificar los imaginarios y formas de representación contemporánea del sujeto social reconociendo la radical historicidad y los puntos de fuga posibles. En las siguientes páginas, realizaremos una crítica materialista del ciberactivismo a partir de algunos aportes fundamentales para una interpretación sociocrítica de los procesos de movilización y acción colectiva en Internet.
\end{abstract}

Palabras clave. Ciberactivismo, Castoriadis, redes sociales, imaginario social, comunicación.

\section{COLLECTIVE IMAGINARIES AND CYBERACTIVISM: A READING FROM CASTORIADIS}

* Catedrático de Teoría de la Comunicación en la Universidad de Sevilla, España. Correo electrónico: fcompoliticas@gmail.com 
ABSTRACT. The digital creation is son the defining base of current breaking-off processes which new urban movements star in. In the present protests cycle that began in 2011 -from arab spring at Yo soy $132-$ it is remarkable how negative processes, rebel imagination and resistence are demanding a new conceptual framework in order to understand the nature of transformations of new social movements. A critical reading of cyberactivism goes through collective imaginaries and contemporary ways of representation of social individual recognizing the radical historicity and the possible vanishing points. On the following pages, we will execute a materialistic review of cyberactivism from some fundamental contributions to develop a socio-critical interpretation of protests and collective action on the Internet Galaxy.

KeY words. Cyberactivism, Castoriadis, social network, collective imaginary, communication.

\section{INTRODUCCIÓN}

En la dialéctica autonomía-heterodeterminación, Castoriadis distingue la creación como elemento central de constitución del sujeto frente a la lógica ilustrada del racionalismo cartesiano. En sus propios términos, "lo histórico-social es creación: creación de una vez y para siempre (institución y significación son irreductibles a lo biológico), creación en cada caso de su institución por parte de cada sociedad. Lo histórico-social es, Por consiguiente, la creación que pertenece al ser/ente" (Castoriadis, 1998, p. 31). Ello presupone una crítica del determinismo y la lógica de la reducción positivista de la Economía Política, tanto como de la indeterminación del individualismo metodológico tan común hoy en lecturas autonomistas del ciberactivismo que proliferan tanto en la investigación como en el propio activismo digital. Pensar la productividad social y el uso de las nuevas tecnologías en procesos de intervención y acción colectiva apunta, desde este punto de vista, a la necesidad y pertinencia de un abordaje sociopráxico de la mediación 
social, considerando la dimensión cultural asociada al nuevo ecosistema informativo como un proceso de construcción.

La potencia transformadora del sujeto tiene lugar en relación con otros en tres planos que Castoriadis distingue como esferas diferenciadas de mediación entre sujeto y sociedad:

- Esfera Privada (Oikos)

- Esfera Público/Privada (Ágora)

- Esfera Público/Pública (Ecclesia)

En el capitalismo, Castoriadis advierte, al igual que Habermas (1981), que las oligarquías liberales comparten con los regímenes totalitarios, el despotismo asiático y las monarquías absolutas el rasgo distintivo de que la esfera pública/pública (la ecclesia) es, de hecho, en gran medida, privada (Castoriadis, 1998, p. 84). "Es la retirada de los pueblos de la esfera política, la desaparición del conflicto político y social lo que permite que la oligarquía económica, política y mediática escapen de cualquier control. Y esto, de aquí en más, produce regímenes de irracionalidad llevada al extremo y de corrupción estructural" (Castoriadis, 2004, p. 23). La emergencia de los nuevos movimientos sociales en red obedece fundamentalmente a la voluntad de recuperar, ocupando la plaza y la esfera pública, la autonomía de la política en procesos instituyentes de proyección, aún en el plano simbólico, de la voz y la potencia creativa de las multitudes conectadas en red. Una interpretación emancipadora y materialista del activismo digital pasa por reconocer este hecho incontestable, considerando en su radicalidad histórica la singularidad y compleja forma de articulación de la experiencia concreta del ciberactivismo como praxis transformadora con los procesos generales de mediación y reproducción social. Cinco tesis sostienen, a nuestro juicio, la pertinencia de esta lectura, siguiendo a Castoriadis, en la comprensión de las actuales formas de conjunción, identificación y proyección social del activismo digital. A saber:

- La historia es una creación humana y nuestro tiempo es el tiempo de la apertura de formas creativas de producción de lo común. La historia es el campo en y por el cual el sentido 
emerge como creación humana. Y la libertad es el acto en la que el sentido se manifiesta a partir de la intermediación psíquica.

- La creación no es predecible ni producible mecánicamente, como los nuevos movimientos urbanos y el ciberactivismo no son determinados a priori, pese a la potencia del cálculo implícito en la lógica del algoritmo que gobierna las redes sociales. En otras palabras, no hay autonomía sin vida, ni vida sin autotransformación.

- La revolución y emergencia de los movimientos de protesta globales que tienen lugar con el ciberactivismo son formas de extensión de la autonomía no solo a nivel de los repertorios simbólicos como la mayoría de la literatura argumenta (Sierra, 2021). Esta, como observamos en la tecnopolítica contemporánea, es, fundamentalmente, gestión colectiva como institucionalidad permanente y creativa de la colectividad, como un acto creativo, como una praxis de dominio del proceso histórico-social.

- La realización del ser como creación es el principio ontológico presente en las nuevas formas emergentes de autogestión informativa que sostienen, hoy por hoy, toda revolución o movimiento de protesta.

- El movimiento por la autonomía de los actuales movimientos sociales ha de afrontar, en congruencia, la heteronomía de las creaciones humanas y la determinación de la economía política capitalista. La autonomía, en fin, presupone la oposición al imaginario instituido y autonomizado desde nuevas matrices y formas de expresión que se concatenan en las redes de intercambio simbólico.

En otras palabras, en toda forma de activismo y lógica instituyente de los imaginarios radicales que recorren, transversalmente, las experiencias contemporáneas de protesta, a lo largo y ancho del planeta, siempre operan cuatro principios consustanciales a las actuales formas magmáticas de vida en común. A saber:

a. Principio de remisión. Toda institución social presupone una red simbólica que tiene un componente real y otro imaginario. 
La enajenación remite a la autonomización del momento imaginario de la institución.

b. Principio de selectividad. Toda intervención social es contingente y presupone una toma de partido. La dimensión magmática que explora Castoriadis da cuenta, en este sentido, de la plasticidad y dinamismo latente en la imaginación humana en su flujo proyectivo y autónomo.

c. Principio de incompletitud. Todo imaginario y el actuar del ciberactivismo opera por selección y por actualidad. Todo imaginario urbano y de los conjuntos de acción se producen en movimiento. Como diría E. P. Thompson, no son clases subalternas ya definidas a priori, la economía moral de la multitud siempre está siendo (Thompson, 2002).

d. Principio de clausura. Es por ello preciso estudiar en los nuevos movimientos sociales los procesos de ensamblaje y articulación y la función vicaria de las tecnologías digitales en tales procesos de autoorganización tal y como hemos venido haciendo en el grupo CIBERMOV (www.cibermov.net).

\section{ELEMENTOS PARA UNA CRÍTICA MATERIALISTA DEL CIBERACTIVISMO}

Considerando los aportes de Castoriadis antes expuestos, a modo de síntesis, hay cuando menos que tomar en cuenta en la perspectiva transformadora los siguientes elementos de análisis para una crítica praxeológica del ciberactivismo, que pasamos a desglosar.

\section{La centralidad de la dimensión subjetiva}

En su Crítica de la Economía Política (1859), Marx concluye que la producción capitalista produce no solo un objeto para el sujeto, sino también un sujeto para el objeto. La cuestión es comprender, desde esta perspectiva genérica, la naturaleza del sujeto de transformación de movimientos como el 15M, conocida como Spanish Revolution. Con independencia del debate conceptual sobre la singularidad generacional de los millenials, la figura del actor-red o la forma del sujeto ciborg, 
hoy sabemos que la actividad autónoma del llamado cognitariado, la tercerización, la intelectualización de la fuerza de trabajo, la robotización e informatización de las tareas productivas, dan cuenta de una transformación de largo alcance que se inicia en los años setenta y se manifiesta de forma evidente en la gloriosa década neoliberal, dando lugar a un nuevo sujeto que debe estar en la base de comprensión del ciberactivismo y los nuevos movimientos sociales.

De acuerdo con Rossana Reguillo, es preciso repensar las nuevas mediaciones a partir de preguntas fundamentales sobre la nueva cultura política de los actores sociales. En otras palabras, es preciso comprender los procesos de las nuevas generaciones, más allá de lecturas reduccionistas, a partir de los paisajes insurrectos, "el espacio tiempo del llamamiento a una revuelta de la imaginación en el que es posible pensar y sentir de otro modo, con otros y otras, a través de la acción colectiva y conectiva" (Reguillo, 2017, p. 11). Por lo mismo, la crítica de la mediación, desde una lectura praxiológica, se torna más que pertinente. Pues desde el punto de vista de los procesos de subjetivación, para vivir debemos comunicar y para comunicar debemos liberarnos del control de la comunicación. El tema revolucionario, que es el mismo que el de los procesos de subjetivación, es la toma de posesión de la comunicación como ámbito creativo de la multitud de las singularidades; es, por consiguiente, la afirmación ontológica de la comunicación liberada. En otras palabras, la comunicación se convierte en horizonte humano en la que es el contexto de un proceso de liberación (Negri, 2006). Un ejemplo ilustrativo de esta lógica son las formas de consumo y coproducción transmedia.

Las actuales prácticas de lectura-escritura tienden a convertirse en un proceso que, en la inmediatez, a diferencia de los procesos anteriores en las que el compartir implicaba siempre un diferimiento, son estructurantes para el ecosistema construido todavía alrededor y a partir del contenido troncal. Un ecosistema cada vez más determinado por el espacio de conversación, por el tiempo de colaboración y la alternancia de roles entre emisores y receptores. Un ecosistema que mejor opera cuanto más logra insertar el texto en un universo simbólico permeable donde reina un cierto 
espíritu de colaboración para la interpretación de los hechos y la creación de nuevas historias (Irigaray/Reno, 2016, p. 22).

En esta dinámica, la transmedialidad transforma performativamente al sujeto (lógica fandom), expande y profundiza narrativas diversas desde la construcción transformadora de mundos posibles, facilita la inmersión y extracción de contenidos georeferenciales, así como procesos y mapas tridimensionales con tiempos, espacios, relaciones y procesos de transformación situados y abiertos al trabajo de la imaginación de los actores sociales. La actualidad o vigencia de las anticipaciones de Castoriadis cobra así hoy pleno sentido si analizamos las formas de producción social autónomas que tienen lugar con la cultura digital.

El dominio de las tramas múltiples, la virtuosidad de los potenciales usos creativos de los contenidos multipantallas dan cuenta, en otras palabras, de una nueva antropología de la modernidad líquida que es necesario problematizar desde la Teoría Crítica pensando cuestiones nucleares que la obra de Castoriadis anticipara décadas atrás, no casualmente, en el marco de la sociedad de consumo. Así, las mediaciones entre bios virtual y cotidiano que definen las actuales condiciones existenciales, y desde luego las formas desbordadas de producción, dan cuenta de una nueva composición y sensibilidad de la fuerza de trabajo que no puede ser ignorada, considerando las transformaciones estructurales que pueden documentarse en el sistema de producción social y que a partir de conceptos como el de creación y los problemas sobre la autogestión y los procesos instituyentes que forman parte de su obra nos ayudan a comprender integralmente la nueva lógica de la mediación social.

Hoy la actividad productiva ha sido radicalmente transformada movilizando nuevas capacidades cognitivas, afectos e información, lógicas de cooperación social y socialización del saber-hacer productivo. Ello no significa reeditar una suerte de determinismo tecnológico, sino más bien reconocer la existencia de nuevas relaciones de producción y formas de trabajo cooperativo inéditos que sitúan en el centro de análisis un nuevo sujeto histórico de transformación que opera en red proyectando todas las potencialidades del mundo virtual. 


\section{El problema de la innovación social}

Un elemento tensional definitorio del trabajo de Castoriadis para repensar el imaginario radical de la cibercultura en esta línea es la dialéctica de la determinación y la creación. Sabemos que hoy la intelectualidad difusa expande las formas de trabajo creativo y las fuentes de riqueza social general.

Las formas de sumisión cada vez más sofisticadas, que afectan más al desarrollo de la productividad que a la extensión del tiempo de trabajo, están ligadas también a formas nuevas de cooperación que engendran un trabajador colectivo, de tal manera que éste, organizándose sobre sus propias bases, desarrollando su independencia organizacional y comprometiéndose cada vez más resueltamente en la lucha contra el capital, tiende a constituirse en un nuevo sujeto histórico (Laval/Dardot, 2015, p. 255).

Ahora, lo nuevo:

no es cualquier cosa, es nuevo en y por esa historia. No todo es posible, sin duda: en la medida en que la realidad está definida, también a su vez define, lo cual quiere decir que está determinada y es determinante; lo nuevo jamás puede ser verdaderamente nuevo a menos que posea un sentido respecto de lo que existe ya, pues de no ser así no sería nuevo, sería inaprensible, innominable, irreal. Pero lo nuevo no es nuevo solamente porque hace que aparezca un nuevo sentido, sino que da otro sentido a lo que ya estaba allí cuyo sentido se podría pensar hasta entonces como determinado, definido, cerrado (Castoriadis, 2011, p. 138).

Sin incurrir en la mixtificación del paradigma reticular o las tesis de Castells sobre la sociedad-red, ciertamente no es posible negar la lógica descentralizada de la organización del trabajo y, en general, de la producción social y económica del tardocapitalismo.

La lógica del llamado new management ha desplegado, como es comprobable empíricamente, formas autónomas de comando cuya máxima 
expresión es la figura del prosumidor y el consumo colaborativo en tanto que modelos de sostenibilidad de la reproducción ampliada del capitalismo, lo que plantea nuevas cuestiones a la hora de distinguir trabajo, profesionalidad o procesos de valorización en la era de la cocreación y del amateurismo.

La denominada economía colaborativa no debe ocultarnos, no obstante, que en los discursos de la cultura emprendedora y de la innovación, como base de desarrollo del capitalismo, preexiste una lógica de ingeniería social de explotación y la ley de hierro del capital del nuevo gerenciamiento postfordista. Ahora, si de acuerdo con Castoriadis, la mirada materialista es la construcción de conocimiento sobre lo nuevo, la teoría crítica debe afrontar estas nuevas realidades de las formas mancomunadas de producción, distribución y consumo desde nuevas matrices que partan de la praxis instituyente y la dimensión comunicacional, agujero negro del marxismo.

En otras palabras, convendría releer los signos del cambio de nuestro tiempo desde la ambivalencia y contradicciones que permea la experiencia productiva y política de los actores sociales, analizando las huellas de lo productivo en la relación entre el ser social y la conciencia posible. Esta idea o noción de experiencia remite al concepto de mediación y al proceso de determinación que hace posible la reproducción social. Pero un análisis consistente de la mediación pasa por asumir la dimensión cultural, construida, de todo medio e innovación.

La crítica del evolucionismo tecnológico significa cuestionar en este sentido la idea marxiana de progreso como un proceso cuasi natural de la sociedad capitalista al comunismo tecnológico donde se confunde, de Marx a Negri, la socialización de competencias y la asociación consciente como característica cooperativa inalienable de toda forma de trabajo en la modernidad capitalista. Sabemos que la reciprocidad y obligación no son procesos naturales, sino lógicas contradictorias de construcción social. En este sentido, cabe reconocer, que "el socialismo se plantea como problema la institución de la cooperación económica y social, (y es resultado) de la fórmula de la asociación libremente consentida y colectivamente gestionada por los productores" (Laval/Dardor, 2015, p. 105). 
De Bajtín a Moles, sabemos que la innovación es un proceso de mediación en el que la idea se materializa en una diferencia como ruptura de la repetición, siendo la capitalización una expropiación de la comunicación dada por la privatización de los bienes públicos, característica de las formas parasitarias de acumulación. En este marco, cabe recordar que la lectura de Marx en los Grundrisse no es determinista tecnológicamente.

Castoriadis resalta la ambivalencia y opacidad de la lectura de Marx. Por ello aconseja una recepción desde nuestro tiempo y situación como Marx mismo hubiera hecho con relación a los cambios tecnológicos en curso. Esto es, la producción y la tecnología son formas socialmente constituidas. Por lo tanto, no se deberían identificar las tecnologías simplemente como parte de las fuerzas productivas que entran en contradicción con las relaciones sociales capitalistas de forma unívoca. Procesos como la telemorfosis y la lógica Lean Production así lo evidencian. Pero una de las características del postfordismo en la posmodernidad contemporánea ha sido la asunción de la lógica del fetichismo de la mercancía, y como consecuencia cierta suerte de idealismo tecnocomunicacional. Así podríamos definir nuestro tiempo por:

a. El ilusionismo de la abstracción del capital financiero.

b. El fetichismo tecnológico.

c. El mito del empoderamiento ciudadano.

d. La ilusión de la descentralización.

e. La apología del cambio social confundido con la aceleración del proceso de circulación del capital por acción de los flujos de información.

f. La ilusión de la falsa transparencia negada por la opacidad de los dispositivos de control de la fuerza de trabajo y de la ciudadanía en la era Echelon.

g. La psicopolítica de las relaciones personales colonizadas por la forma mercancía.

Muchos de los debates sostenidos a lo largo de las últimas décadas en la literatura especializada sobre cibercultura tienden a olvidar la importancia de la lógica social que gobierna esta cultura o era del acceso. Sin 
negar que el papel de la técnica es central y que, como advirtiera Marx, fue la producción de objetos físicos lo que permitió que se desarrollara el yo y las relaciones sociales de la modernidad, la consideración de la dimensión creativa de la cultura libre de intercambio que facilitan las tecnologías digitales presupone exponer el papel central de las ecologías de vida a este respecto, repensando la organización social de la vida inmediata como un problema de ensamblaje de las esferas distinguidas por el autor.

Esta es la hipótesis del clinamen, de la forma comunidad que algunos antropólogos reivindican y que se antoja más que nunca pertinente para entender las formas de trabajo y producción de riqueza en la era del capitalismo cultural y el origen de los nuevos movimientos de protesta globales. En otras palabras, la creación como producto compartido pasa, de acuerdo con Laval y Dardot, por concebir lo común no como un proceso natural, sino como el producto del capital

y más exactamente de su poder sobre el trabajo mediante la organización de la cooperación productiva. En suma, según Marx, es el capital, en su frenesí de enriquecimiento, el que produce lo común por su propio interés, al hacer de la fuerza colectiva de los trabajadores por él organizada la fuerza colectiva del capital (Laval/Dardot, 2015, p. 217).

La cuestión aquí es el problema de la institucionalidad, de la organización. El problema de la dialéctica entre lo instituido y lo instituyente es la organización de la comunicación (el nosotros del homo faber). Qué tipo de regulación autónoma de las prácticas es posible, porque entre el ethos romántico precapitalista y la imagen idealizada de la autonomía y autorregulación de los actores locales podemos incurrir en lecturas, diríamos, poco productivas. Por lo mismo, se torna pertinente analizar las contradicciones entre la abstracción y lógicas expropiadoras del capital y las ecologías de vida con sus formas particulares de comunidad y religancia, en el proceso, en fin, de adaptación creativa que las culturas populares despliegan con la apropiación de los recursos tecnológicos. 
Tiempo, acontecimiento y mundo de vida

En términos de Negri:

el tiempo de la cooperación se constituye como sujeto contra el capital. Es valor de uso. Es principio de crisis, latente o efectivo, pero siempre principio de crisis. En la literatura marxiana el valor de uso se interpreta con frecuencia como fundamento naturalista o como mera función del valor de cambio. Estas concepciones eran todavía posibles, alternativa o ambiguamente, antes del paso a la subsunción real. En la fase de la subsunción el tiempo se presenta como substancia colectiva del valor y como sujeto antagonista (Negri, 2006, p. 122).

De acuerdo con las tesis de Dallas Smythe, el tiempo colonizado por la industria del espectáculo

es un tiempo libre en el que trabajamos para la preservación del sistema, es el tiempo de producción de la plusvalía ideológica. La energía síquica permanece como atención concentrada en los múltiples mensajes que el sistema distribuye... se trata de un tiempo de nuestra jornada que no es indiferente a la producción capitalista, sino al contrario: es utilizado como el tiempo óptimo para el condicionamiento ideológico (Silva, 1979, p. 205).

Y es por ello que un tiempo libre es contrario a un tiempo en la que "los hombres pasan su tiempo sin sentido y permanecen en realidad sujetos a los ritmos del trabajo y a su ideología" (Silva, 1979, p. 205). En otras palabras,

el tiempo es la naturaleza en la cual la vicisitud de la subsunción se realiza. El tiempo medido es la ontología negativa del poder de mando y el tiempo de la vida es la ontología constitutiva del rechazo, de la alternativa, de la liberación. A la negación de todas las posibilidades de que se compone la tautología sistémica del poder de mando, se opone el conjunto de todas las posibilidades 
que constituyen la contradicción existencial del sujeto colectivo (Negri, 2006, p. 75).

Por lo mismo, cuando problematizamos la centralidad tecnológica precisamos repensar la dominación como un problema de economía política del tiempo de vida, repensar el oikos.

Todo modo de producción genera una experiencia espaciotemporal determinada. La regulación y control social tiene lugar mediante la segregación de una temporalidad y organización de la experiencia en el espacio, por lo general codificada. Cabe en este sentido preguntarse, como apunta Jameson (2013), si un análisis de la temporalidad a partir de Marx nos permitiría actualizar nuestra comprensión de la cultura contemporánea, considerando más integralmente la compleja relación entre la temporalidad existencial y el sistema de producción, de forma más concluyente y exhaustiva en lo que Ludovico Silva denomina cultura de Alicia en el país de las mercancías, basado en el perfetichismo del capital cultural. La llamada Economía de la Atención, propia de la ficcionalización del Capitalismo Financiero, plantea en esta dirección un reto para una crítica desde el materialismo cultural si, como creemos, hemos de repensar mejor los tiempos de trabajo y de intercambio en un sentido productivo. Las redes, flujos, vínculos y valores creativos tienen siempre una dimensión simbólica y material, pero, pese a la lógica del don, prima siempre una estricta y determinada economía política del tiempo que cabe observar a partir de la ley de hierro del Capital.

Reconociendo que el modo capitalista de explotación hoy está estructurado en torno a los dispositivos electrónicos, una teoría crítica debe, en consecuencia, articular su análisis a partir de estas estructuras comunicacionales de colonización de los mundos de vida y sus formas de organización de la experiencia. Así por ejemplo el tiempo de consumo hoy es más determinante para la identidad y la reproducción del sujeto que el tiempo de trabajo, cuantitativa y cualitativamente. La tradición crítica, si asume radicalmente la lógica del pensamiento relacional que distingue como visión holística la lectura de Marx, ha de problematizar en consecuencia esta dimensión central en la era de la biopolítica como Castoriadis planteara en los debates de Socialismo o Barbarie (Moreno Pestaña, 2019). 
La política del deseo

El imaginario radical que hoy gobierna el capitalismo corresponde, siguiendo a Castoriadis, al nivel histórico-social como creación del colectivo anónimo, no está formalizado, ni es formalizable, pues se alimenta de representaciones, afectos y deseos siempre fluctuantes e inestables. La metamorfosis del capitalismo nos obliga, en esta dirección, a una mayor reflexividad sobre procesos singulares relativos a la experiencia del sujeto y a la generación del valor en el plano psicopolítico, al ser un problema central de la apariencia y el fetichismo de la mercancía característicos de la era del capitalismo ficción. Entre otras razones porque el capitalismo es un sistema de regulación social no consciente. Del mismo modo que es inseparable lo material en todo registro cultural o simbólico, el trabajo, como actividad productiva, es una operación semiótica con una dimensión proyectiva insoslayable. No hay producción sin dirección, sin deseo de transformación, sin dimensión pro/yectiva. Luego, la corporalidad del lenguaje y el trabajo, la dimensión discursiva del proceso de producción de los cuerpos, el adentro del cerebro con el afuera del mundo y la superficie del inconsciente con la del cuerpo sin órganos, remiten a una problematización del deseo.

Las referencias de Marx a la idea de apariencia, de mostrarse, frente a la esencia de la naturaleza del trabajo como explotación da cuenta de la importancia asignada al fetichismo de la mercancía como representación, a la lógica espectral, que diría Derrida (1995). Esta dimensión imaginaria es la base necesaria de la creatividad en las formas de producción contemporánea y es propia de la facultad de formar, transformar e imaginar, "facultad de producción de fantasmas -o fantasmatización- que precede a toda organización, aunque sea primitiva de la pulsión (y que) Castoriadis la llama imaginación radical o bien inconsciente" (Laval/Dardot, 2015, p. 484). Ello nos lleva a una lectura más praxiológica, instituyente y autónoma de la actividad productiva con relación a las nuevas lógicas de acción colectiva.

El tema del deseo, de la mediación cognitiva y afectiva del inconsciente y la producción del imaginario, constituye un punto de partida inexcusable para una consideración contemporánea de la tecnopolítica contemporánea. Como bien apunta Muniz Sodré (2014), el trabajo de 
relacionar, poner en común, (syn-ballein) formas separadas, a modo de un equivalente general, circulante como moneda, falo, padre, monarca o signo, la mediación simbólica, en fin, con la que se produce la economía, la psique individual, la política o los intercambios, son centrales en los modos de producción social del capitalismo y forma parte de estrategias de inducción subliminal más que determinantes, tal y como venimos argumentando.

En la misma línea, pensar la mediación social del capitalismo exige, de acuerdo con este razonamiento, poner de relieve "la relación entre la representación y la representabilidad tal como la encontramos en Freud, donde la construcción inconsciente del sueño explora el significante en busca de elementos utilizables y bloques de construcción, en busca de la presentación/representación del deseo y la pulsión" (Jameson, 2013, p. 16).

El retorno a la materialidad de la imagen fantasmagórica de lo real se antoja por ello, a este respecto, crucial si tomamos en serio la prevalencia en nuestro tiempo de la cultura zombi del capitalismo de lo libre. Como ilustra Derrida, la idea de espectralidad revela, en este punto, la necesidad de deconstrucción de la materialidad de toda medición social. Debord (2010) lo señala al explicar la lógica del proceso de acumulación del capitalismo tardío como disyunción en un régimen de visibilidad que ordena el espacio y la experiencia temporal en términos de producción de la subjetividad y, desde luego, del régimen escópico de acumulación.

En otras palabras, el espectáculo, en el capitalismo ficción, es el capital devenido imagen. La racionalidad técnica de la ecosofía mediática de lo espectacular integrado constituye así la esencia de la figuración ficcionalizada de la comunicación que hace posible el proceso de explotación de la fábrica social cuya máxima expresión es el dinero. La cuestión de la imagen o figuración es, por lo mismo, relevante porque constituye un problema estratégico del marxismo, más allá de Derrida. Se trata, en suma, de un problema ideológico central para comprender la captura total de la vida por el Capital que, para ser de facto comprendido en su integridad, nos exige reconocer la radical historicidad y al tiempo el sentido de la representación en todo su espesor material. Una lectura reinterpretada a la luz de nuestro tiempo del problema 
del Clinamen de Epicuro adquiere así relevancia en la afirmación de la singularidad del consumo como proceso autónomo de producción del sujeto y configuración de su imaginario, retomando así algunas de las cuestiones nucleares de la autonomía según Castoriadis.

\section{La mediación social de la teoría}

"El imaginario no es la producción de imágenes, es la creación de un mundo humano; y no sólo en el nivel de la psique individual, sino en el nivel del campo histórico-social. Es evidente que hay un imaginario de la democracia; así como la autonomía social e individual es una significación imaginaria social" (Castoriadis, 2004, p. 123). La filosofía de la praxis cuestiona en este sentido la determinación y la función de la práctica teórica como un campo ajeno a la mediación social. La crítica al marxismo como discurso científico cerrado, autorreferencial, inacabado y con dificultades de renovación están en la base de la crítica que Castoriadis lideró en Socialismo o Barbarie y la propia Internacional Situacionista al desplazar la acción política al plano simbólico para trabajar la imaginación.

En esta línea de continuidad, el situacionismo influyó notablemente la guerrilla semiótica en las calles, desde la cultura graffiti y el arte urbano a hoy el activismo digital en los nuevos movimientos por el derecho a la ciudad. Pero más allá aún renovó desde el marxismo heterodoxo una lectura materialista de las nuevas formas de mediación que deben ser retomadas para comprender fenómenos emergentes como el ciberactivismo, en virtud de una nueva concepción de la relación teoría y práctica, un tema muy recurrente en la obra de Castoriadis por ser el núcleo gordiano de muchas cuestiones sustanciales, tal y como hemos visto en otros autores como Sánchez Vázquez o Bolívar Echeverría (Sierra, 2021).

La teoría del conocimiento de Marx, relacionando trabajo y conciencia, debería entenderse como una teoría que aprehende las formas de la mediación social, más que el trabajo (o la clase), significa que la teoría social del conocimiento de Marx, relacionando trabajo y conciencia, debería entenderse como una teoría 
que aprehende las formas de la mediación social (constituidas por tipos estructurados de práctica) y las formas de la subjetividad como intrínsecamente relacionadas. Tal teoría no tiene nada en común con una reflexión teórica del conocimiento, ni con la noción de que el pensamiento es superestructural. También se opone a la común identificación de una teoría materialista de la subjetividad con una teoría de los intereses únicamente (Postone, 2006, p. 492).

El salto cualitativo ya no es solamente material sino también formal y cultural, y tiene en la imagen un campo de problematización en cuanto que esta relación es una relación reflexiva indirecta.

En términos de Marx, lo concreto es la síntesis de múltiples determinaciones y, por ende, el conocimiento la representación del proceso de síntesis que desde la práctica crítica exige un desborde, una interpretación liberadora, característica del materialismo cultural. Ello presupone una formalización. La forma es el límite que separa una totalidad de su medio entorno. Esta puede ser una distinción tanto física o territorial como económica, política y/o cultural. Ello implica una lectura otra, sugerida por Castoriadis, en el sentido de apuntar a la semiosis ilimitada. Esto es, las significaciones no están plenamente determinadas pese a su localización. Y ello porque existen principios como el de remisión, selectividad, combinación, incompletitud, clausura y actualidad que abren el imaginario radical al magma de significaciones potenciales que todo sujeto construye en la dialéctica de la heteronomía y la autonomía, según hemos señalado. Ello exige problematizar el General Intellect. La teoría de redes de valor ilustra que cuanto más se socializa el conocimiento más valor adquiere este. Y remite al problema de la forma institucional. La organización implica, en el caso de la disputa por el código, una irreductible contradicción o tensión dialéctica entre lo material y lo inmaterial. Podemos hablar de

una doble articulación del lenguaje de los objetos, según Echeverría, definida por una articulación material insuperable, y una creación libre de formas, y, en ese nivel, una suerte de relación inversamente proporcional entre la materialidad del objeto y su 
carga semiótica: en uno de los extremos, la palabra, vaporosa, casi inmaterial y dotada de una poderosa capacidad de semiosis; en el otro, la maquinaria industrial, maciza, densa, hierática y casi inexpresiva (Moraña, 2014, p. 147).

El propio Marx fue más que consciente de este hecho. De ahí la pertinencia como intuyera Echeverría de

revincular esta discusión a los conceptos de trabajo y relaciones sociales de producción (lo que) podría conducir a una radicalización de la crítica a la semiótica desde la identidad producción-significación, permitiendo llevar adelante el segundo paso de esa crítica: la puesta en cuestión en sus fundamentos teóricos desde la crítica de la economía política (Chávez, 2015, p. 86).

En este proceso, no se puede eludir la mediación social de la teoría. Considerar esto es un primer paso para, a nivel metateórico, discutir el horizonte conceptual del ciberactivismo y la aleación, en palabras de Blanchard, entre cognitariado, activistas sociales y nuevo precariado, protagonistas del ciberactivismo en nuestros días.

\section{CONCLUSIONES}

En la era postmedia, el reino de lo extraordinario y de lo espectacular integrado, captura y subsume la creatividad como norma fundamental de acumulación en el tardocapitalismo. Pues el trabajo, como toda creación, es un proceso de mediación social. Además de la cualidad objetiva, todo objeto, también la mercancía de la fuerza trabajo, está imbuido por relaciones sociales, sentidos y representaciones que dan cuenta de la mediación social y las transformaciones de cada época que construimos como actores. Como vindicara en sus escritos el propio Marx, toda verdadera filosofía debe por lo mismo ser la quintaesencia intelectual de su tiempo, y en la era de Internet hemos de pensar la realidad desde nuevas categorías y herramientas de análisis.

Ahora, la crítica de Castoriadis a Marx es que no reconoce la dimensión instituyente de lo social pese a su voluntad de producir una 
filosofía de la praxis. Esta dimensión, la creativa, es, a nuestro juicio, vital para comprender los nuevos procesos de acción colectiva emergentes, pese que a la mayoría de la literatura especializada se centra casi exclusivamente en la dimensión racional de las oportunidades, recursos y repertorios simbólicos de actuación. Considerar este marco teórico conceptual presupone, en consecuencia, abordar la dimensión imaginaria del ciberactivismo en los nuevos movimientos urbanos, pensar prioritariamente:

- Los procesos de ensamblaje y creación social

- Las emociones y dialéctica performativa de la interacción social

- La simbolización

- Las normas y reglas prácticas de autoorganización

- Y el universo de los imaginarios instituyentes

La teoría social de la mediación es, como hemos tratado de explicar, un eje neurálgico de análisis desde este punto de vista más que obligatorio. Y que Castoriadis anticipa de forma productiva.

Las revueltas de la imaginación que han sacudido el paisaje global en este otoño civilizatorio, en tanto acontecimientos irruptivos que horadan los horizontes de posibilidad, no pueden ser definidos desde un mapa de sentidos previamente determinados. Las insurrecciones en clave tecnopolítica, no son una revolución, son acontecimiento, potencia, ruptura (Reguillo, 2017, p. 190).

De ahí la actualidad de la filosofía de la praxis y el principio de autonomía que es preciso explorar en la experimentación de la tecnopolítica como transgresión de la contradictoria articulación entre existencia (política) y concepto (símbolo y vida). La vindicación en suma de la autonomía en la era de la cultura red es un proyecto histórico-social para liberar las potencialidades de la inteligencia creativa de los sujetos y colectivos humanos. Pues todo proceso de transformación, en la base de los actuales movimientos ciberactivistas, no procura otra cosa que un cambio instituyente en las formas de organización de la sociedad misma por medio de la autotransformación de un tiempo nuevo. Del 
determinismo causal a la potencia del hacer y del actuar humano, Castoriadis apunta, en fin, bases teóricas para comprender las multitudes inteligentes, la capacidad incesante de la creatividad de las masas para sustentar una crítica materialista de las formas contemporáneas de mediación social.

El desbordamiento de la autonomía justifica esta aproximación teórica, considerando que lo teórico, en palabras del propio autor, siempre está subordinado a la praxis. "La teoría (también la de la cibercultura y el activismo digital, añadiríamos nosotros) debe en efecto comprenderse como modo y momento de la praxis: el momento de la creación constituye el momento práctico de la teoría misma, pues la creación forma el momento esencial de la libertad efectiva del sujeto" (Poirier en Castoriadis, 2011, p. 14). La creación es una mediación sobre las determinaciones, un proceso de libertad y necesidad, en la medida que resulta una apertura de posibilidades nuevas, una apertura cognitiva que, en nuestro objeto de estudio, el ciberactivismo, exige una mayor imaginación comunicológica y una práctica teórica abierta al campo inmanente de las redes de intervención y disputa del sentido social. Ello pasa por asumir el principio de clivaje y reconocer que, en el ciberactivismo, con independencia del contexto social de referencia, tiene lugar procesos:

- Conectivos en los que la imagen, como dimensión formal, por medio de la mímesis, articula procesos de resistencia y organización de dinámicas instituyentes de los nuevos movimientos sociales.

- Autónomos de nuevos espacios y tiempos liberados del sujeto de transformación frente a la lógica instrumental que gobierna no solo el modelo de producción y acumulación por expropiación del capitalismo, sino incluso el intercambio y socialización en las redes sociales.

- Creativos por la promoción social de nuevos usos y formas de apropiación, liberación y desarrollo compartido de las nuevas herramientas de la revolución digital.

- Proyectivos en la medida que se cultiva la potencialidad (poder-hacer-ser) más allá de las formas de plusvalía semántica de 
carnavalización y resignificación que hacen los movimientos sociales por ejemplo con los memes en el discurso y la esfera pública. La dimensión radical del nuevo imaginario urbano de estos movimientos es justamente el cultivo de las potencialidades liberadoras o disruptivas que acompañan a los nuevos usos y aplicaciones en los procesos de acción y movilización colectiva.

Y este es el momento de la praxis, la transformación del objeto tecnopolítico que nos configura como pedagogía del asombro y construcción indefinida, virtual, del ethos o refugio de la vida en común. Una suerte, en fin, de Tahumazein, de proyección radical que libera la dialéctica de la información y la lógica combinatoria que hace posible y deseable la autonomía que demandan los nuevos movimientos de protesta. Sólo en este plano de observación es comprensible la potencia y alcance de los procesos de movilización y acción colectiva en red.

\section{Fuentes CONSULTADAS}

Blanchard, D. (2007). Crisis de palabras. Notas a partir de Cornelius Castoriadis y Guy Debord. Madrid: Acuarela \& Machado.

Castoriadis, C. (1998). Hecho y por hacer. Pensar la imaginación. Buenos Aires: EUDEBA.

Castoriadis, C. (2011). Historia y creación. Textos filosóficos inéditos (1945-1967). Madrid: Siglo XXI.

Castoriadis, C. (2006). Una sociedad a la deriva. Buenos Aires: Katz.

Castoriadis, C. (2004). Sujeto y verdad en el mundo histórico-social. Seminarios 1986-1987. La creación humana I. Buenos Aires: FCE.

CHÁvez, D. (2015). Valor de uso y contradicción capitalista. Una aproximación al pensamiento de Bolivar Echeverría. Quito: UASB/Corporación Editora Nacional.

Debord, G. (2010). La sociedad del espectáculo. Madrid: Pre-textos.

DeRridA, J. (1995). Espectros de Marx. Madrid: Trotta.

EAGLETON, T. (1998). Walter Benjamin o hacia una crítica revolucionaria. Madrid: Cátedra.

Echeverría, B. (2010). Definición de la cultura. México: FCE. 
ECHeVerRía, B. (1986). El discurso crítico de Marx. México: Ediciones ERA. FisCHBACH, F. (2015). La producción del mundo. En Actuel Marx/Intervenciones. Núm. 18. Santiago.

Habermas, J. (1981). Historia y crítica de la opinión pública. Barcelona: Gustavo Gili.

Irigaray, F. y Reno, D. (Comps.). (2016). Transmediaciones. Creatividad, innovación y estrategias en nuevas narrativas. Buenos Aires: La Crujía.

Jameson, F. (2013). Representar El Capital. Una lectura del tomo I. Buenos Aires: Fondo de Cultura Económica.

Jameson, F. (1996). La estética geopolítica. Cine y espacio en el sistema mundial. Barcelona: Paidós.

Laval, C. y Dardot, P. (2015). Común. Ensayo sobre la revolución en el Siglo XXI. Barcelona: Gedisa.

Mandel, E. (1978). Génesis y estructura de El capital de Marx. Estudios sobre los Grundrisse. México: Siglo XXI.

Marx, K. (1978). Lineas fundamentales de la crítica de la economía politica. Barcelona: Crítica.

Marx, K. (2013). Artículos periodísticos. Barcelona: Alba Editorial.

Mattelart, A. (2010). Para un análisis de clase de la comunicación. Buenos Aires: Cooperativa Gráfica El Río Suena.

Mattelart, A. (2011). Para un análisis de las prácticas de comunicación popular. Introducción a Comunicación y Lucha de Clases. Buenos Aires: Cooperativa Gráfica El Río Suena.

Modonesi, M. (2010). Subalternidad, antagonismo, autonomía. Marxismo y subjetivación politica. Buenos Aires: CLACSO/Prometeo Libros.

Moraña, M. (Ed.). (2014). Para una crítica de la modernidad capitalista. Dominación y resistencia en Bolívar Echeverría. Quito: UASB/El Equlibrista

Moreno, J. (2019). El retorno a Atenas. Madrid: Siglo XXI.

Moulier-Boutang, Y. et al. (2004). Capitalismo cognitivo, propiedad intelectual y creación colectiva. Madrid: Traficantes de Sueños.

Negri, A. (2006). Fábricas del sujeto. Ontologías de la subversión. Madrid: Akal.

Postone, M. (2007), Marx reloaded. Repensar la teoría crítica del capitalismo. Madrid: Traficantes de Sueños. 
Postone, M. (2006). Tiempo, trabajo y dominación social. Madrid: Marcial Pons.

Reguillo, R. (2017). Paisajes insurrectos. Jóvenes, redes y revueltas en el otoño civilizatorio. Madrid: NED EDICIONES.

Sierra, F. (Ed.). (2013). Ciudadanía, Tecnología y Cultura. Nodos conceptuales para pensar las nuevas formas de mediación digital. Barcelona: Gedisa.

Sierra, F. (2021). Ciberactivismo. Valencia: Tiránt lo Blanch.

Silva, L. (2013). A mais-valia ideologica. Florianopolis: Editora Insular.

SiLva, L. (1979). Teoría y práctica de la ideología. México: Nuestro Tiempo.

Sodré, M. (2014). A ciencia do Comum. Río de Janeiro: Editora Vozes.

Thompson, E. (2002). Obra esencial. Barcelona: Crítica.

Zızek, S. (2008-05-1). Mayo del 68 visto con ojos de hoy. En El País. p. 27.

Fecha de recepción: 12 de diciembre de 2019

Fecha de aceptación: 13 de mayo de 2021

DOI: http://dx.doi.org/10.29092/uacm.v18i46.850 